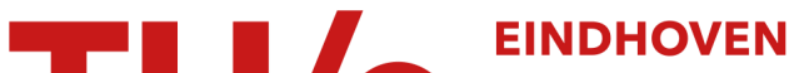 \\ UNIVERSITY OF \\ TECHNOLOGY
}

\section{Magnetic read-only memory with removable medium}

Citation for published version (APA):

Root, op 't, W., Swagten, H. J. M., Jedema, F. J., \& Kuiper, A. E. T. (2005). Magnetic read-only memory with removable medium. Applied Physics Letters, 87(20), 203501-1/3. [203501]. https://doi.org/10.1063/1.2128488

DOI:

$10.1063 / 1.2128488$

Document status and date:

Published: 01/01/2005

\section{Document Version:}

Publisher's PDF, also known as Version of Record (includes final page, issue and volume numbers)

\section{Please check the document version of this publication:}

- A submitted manuscript is the version of the article upon submission and before peer-review. There can be important differences between the submitted version and the official published version of record. People interested in the research are advised to contact the author for the final version of the publication, or visit the $\mathrm{DOI}$ to the publisher's website.

- The final author version and the galley proof are versions of the publication after peer review.

- The final published version features the final layout of the paper including the volume, issue and page numbers.

Link to publication

\section{General rights}

Copyright and moral rights for the publications made accessible in the public portal are retained by the authors and/or other copyright owners and it is a condition of accessing publications that users recognise and abide by the legal requirements associated with these rights.

- Users may download and print one copy of any publication from the public portal for the purpose of private study or research.

- You may not further distribute the material or use it for any profit-making activity or commercial gain

- You may freely distribute the URL identifying the publication in the public portal.

If the publication is distributed under the terms of Article 25fa of the Dutch Copyright Act, indicated by the "Taverne" license above, please follow below link for the End User Agreement:

www.tue.nl/taverne

Take down policy

If you believe that this document breaches copyright please contact us at:

openaccess@tue.nl

providing details and we will investigate your claim. 


\title{
Magnetic read-only memory with removable medium
}

\author{
W. P. E. M. Op't Root ${ }^{a)}$ and H. J. M. Swagten \\ Department of Applied Physics, Center for NanoMaterials (cNM), Eindhoven University of Technology, \\ P.O. Box 513, $5600 \mathrm{MB}$ Eindhoven, The Netherlands
}

F. J. Jedema and A. E. T. Kuiper

Philips Research Laboratories, Prof. Holstlaan 4, 5656 AA Eindhoven, The Netherlands

(Received 3 June 2005; accepted 14 September 2005; published online 7 November 2005)

\begin{abstract}
A solid-state memory concept is discussed, featuring a removable data carrier on which information is stored in a pattern of magnetic bits. The information is read out with a sensor array of magnetic tunnel junctions. The calculated readout signals of the sensors are compared with the measured values for a magnetic card with a data density of $0.5 \mathrm{Mbyte} / \mathrm{cm}^{2}$. The card-sensor separation is identified to determine the ultimate achievable data density. (C) 2005 American Institute of Physics.

[DOI: 10.1063/1.2128488]
\end{abstract}

At present, the most abundant types of data storage are magnetic disk storage, optical disk storage, and solid-state storage. For content distribution to portable devices, a lowcost storage concept could be of interest. Such a storage solution should combine the removability and replicability of optical disk storage with the robustness, power efficiency and small form factor of the well-known flash memory. This letter addresses a storage solution based on a solid-state reader consisting of a two-dimensional (2D) array of magnetoresistive elements, similar to a magnetic random access memory. ${ }^{1}$ However, the information is not stored in the array itself but contained on a separate and removable data carrier. Together, the reader and data carrier form a magnetic read-only memory (MROM).

As sketched in Fig. 1, the binary information on the MROM card is encoded into the topography of the medium via mesas of a ferromagnetic material. For our experiment we produced data carriers on glass substrates, on which a pattern of 100-nm-high mesas was created in resist using e-beam lithography. The rectangular footprint of a single bit measures $1 \times 5 \mu \mathrm{m}^{2}$, the pitch being 4 and $7 \mu \mathrm{m}$ in the $x$ and $y$ direction, respectively, as indicated in the right panel of Fig. 2. This corresponds with a bit density of $0.5 \mathrm{Mbyte} / \mathrm{cm}^{2}$. The medium was completed by sputter deposition of $200 \mathrm{~nm} \mathrm{Co}{ }_{90} \mathrm{Fe}_{10}$ through a shadow mask while applying a magnetic field in the $y$ direction. After the processing the glass plate was sawn into pieces of $6 \times 4 \mathrm{~mm}^{2}$.

The magnitude of the field generated by a bit is calculated analytically by solving the magnetostatic Maxwell equations for a single-domain particle (cuboid) uniformly magnetized in the $y$ direction. The sensor is only sensitive to the magnetic field component in the $y$ direction, which for a single cuboid is

$$
\begin{aligned}
\mathbf{H}_{y}(x, y, z)= & \sum_{i=0}^{1} \sum_{j=0}^{1} \sum_{k=0}^{1}(-1)^{i+j+k} \frac{M_{\mathrm{bit}}}{4 \pi} \\
& \times \arctan \left(\frac{(x-a)(z-c)}{(y-b) \sqrt{(x-a)^{2}+(y-b)^{2}+(z-c)^{2}}}\right),
\end{aligned}
$$

where $M_{\text {bit }}(=8.7 \mathrm{kOe})$ is the magnetization of the $\mathrm{Co}_{90} \mathrm{Fe}_{10}$

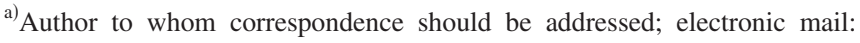
w.p.e.m.o.t.root@tue.nl
}

film, $\quad a=w_{\text {bit }}\left(i-\frac{1}{2}\right), \quad b=l_{\text {bit }}\left(j-\frac{1}{2}\right), \quad c=t_{\text {bit }}\left(k-\frac{1}{2}\right) \quad$ and $w_{\text {bit }}(=1 \mu \mathrm{m}), l_{\text {bit }}(=5 \mu \mathrm{m})$ and $t_{\text {bit }}(=100 \mathrm{~nm})$ are the width, length and topographical height of the cuboid, respectively. The center of the cuboid is taken as the origin of the $x, y, z$ coordinates. Because the CoFe layer is covering the mesas as well as the substrate, the magnetic field of a single bit is the sum of two cuboids. One is on top of the mesa, whereas the other is translated in the $z$ direction with $200 \mathrm{~nm}$ and has an opposite magnetization direction.

To read out the local magnetic fields of the bits we developed a dedicated sensor array of $3 \times 3$ elements, as shown in the left panel of Fig. 2. The dye size of the sensor chip measures $7 \times 7 \mathrm{~mm}^{2}$, its processing has been described elsewhere. ${ }^{2,3}$ A magnetic tunnel junction (MTJ) is located at each crossing of a word and bit line. The two ferromagnetic layers of the MTJ were magnetized in a so-called crossed anisotropy geometry in order to linearize the output signal of the sensor. The sensitivity of the sensor elements was measured to be in a narrow range of $6-8 \Omega / \mathrm{Oe}$. We can use the Stoner-Wohlfahrt (SW) model, ${ }^{5}$ for the magnetization rotation of the free magnetic layer in the MTJ, to calculate the sensitivity. As the length of the free layer electrode is much larger than its height and width, the SW model approximately yields

$$
\left.\frac{\partial R_{\mathrm{MTJ}}}{\partial H}\right|_{H=0} \approx \frac{\Delta R}{2 M_{f}} \frac{w_{f}}{t_{f}},
$$

where $\Delta R$ is the difference in resistance of the MTJ between its parallel and antiparallel state, $M_{f}$ is the magnetization of the free layer in the MTJ, and $w_{f}$ and $t_{f}$ are the width and thickness of the free layer of the MTJ. The MTJs had a resistance $R_{\text {par }}$ in the parallel state in the range of 5.5 $-8.5 \mathrm{k} \Omega$, and an $M R$ ratio of $20 \%, M_{f}=17 \mathrm{kOe}$, and the dimensions of the free layer are $l_{f}=5 \mu \mathrm{m}, w_{f}=1 \mu \mathrm{m}$ and $t_{f}$

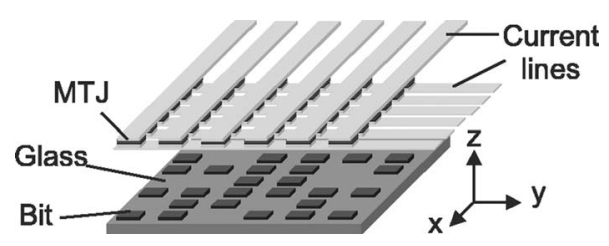

FIG. 1. The MROM card (bottom) is brought into close contact with the sensor array (top), enabling the bits to be sensed by the magnetic tunnel junctions (MTJs). 


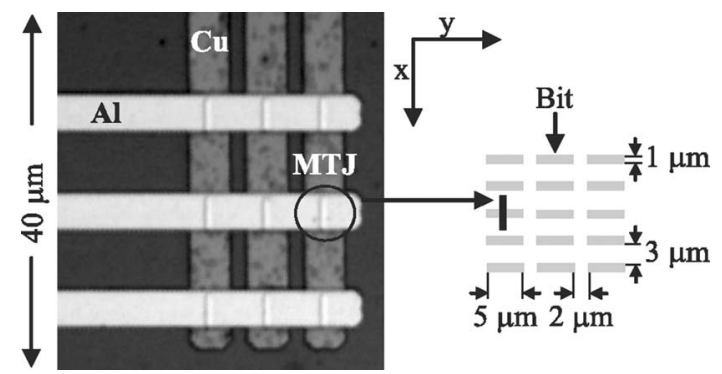

FIG. 2. Image of the sensor array, showing an ensemble of $3 \times 3$ elements. For comparison, a bit pattern is shown schematically at the right for a comparable scale.

$=5 \mathrm{~nm}$. Using these numbers we obtain a calculated sensitivity range of $\sim 6-9 \Omega / \mathrm{Oe}$, which corresponds well with the measured range.

The sensor and the medium are aligned accurately using a double interferometer setup as sketched in Fig. 3. A narrowband laser interferometer allows us to reduce the deviation from parallel alignment of the sensor and bit planes to less than $10^{-3}$ rad. With a broadband (white light) interferometer and a narrowband spectrometer the medium-sensor distance $(z)$ can be determined to an accuracy of $100 \mathrm{~nm}$. The sensor-medium separation distance is defined as the distance from the center of the upper cuboidal bit to the center of the ferromagnetic free layer of the MTJ and can be controlled with a piezo element moving in the $z$ direction. The shortest sensor-medium distance obtainable in our experiments was $z=0.93 \mu \mathrm{m}$, which we ascribe to dust particles present on the processed medium surface.

If the medium is brought sufficiently close to the sensor array, the sensor elements can detect the presence or absence of a bit. Figure 4 shows a 2D plot of the detected signal from a single MTJ in the array when the MROM medium was scanned at a distance of $1.6 \mu \mathrm{m}$ over the sensor. The orientation of the sensor relative to the bits on the medium is shown in Fig. 2. Although the triangular shaped bit pattern on the medium is recognizable, individual bits are not. Oscillations in the $y$ direction with a period of $7 \mu \mathrm{m}$ are visible. However, no oscillations in the $x$ direction are observed. This is attributed to the fact that length of the sensor $l_{f}$ is longer than $4 \mu \mathrm{m}$, the pitch of the bits on the medium in the $x$ direction. At the top of each triangular shaped bit pattern the amplitude of the oscillations is smaller than near the basis of the triangle. This is attributed to the fact that at the basis of the triangle, above a group of bits, the sensor detects more than one bit and hence the signal is larger. In bit-free regions (e.g., $0<x<30 \mu \mathrm{m}$ ) the measured signal fluctuates, implying that the CoFe layer on the substrate is not magnetized homogeneously. These fluctuations were not measured at a large separation distance $(z>10 \mu \mathrm{m})$. When all the MTJs in

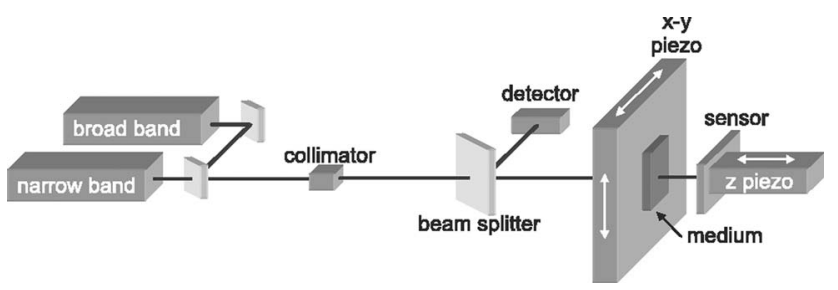

FIG. 3. The setup used to accurately align the MROM card with the sensor array. The medium-sensor distance can be monitored using the

interferometer.
Downloaded 24 Oct 2007 to 131.155.108.71. Redistribution subject to AIP license or copyright, see http://apl.aip.org/apl/copyright.jsp

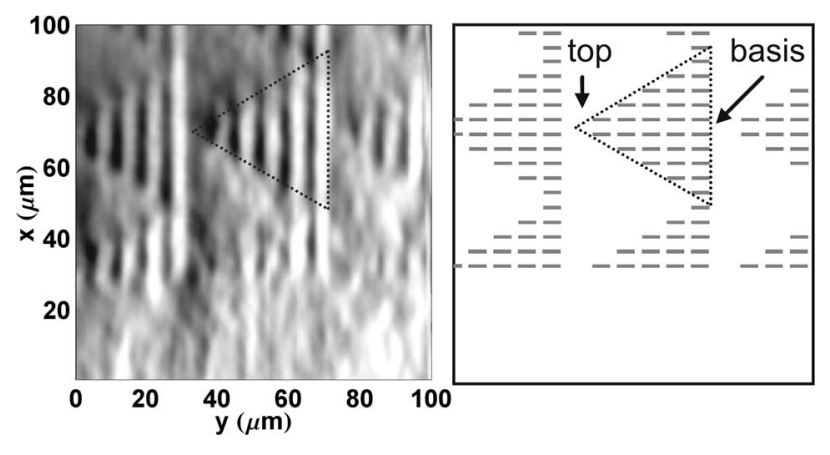

FIG. 4. The measured magnetic field Hy visualized by a gray scale (white $=15$ Oe, black $=5 \mathrm{Oe}$ ). The bit pattern of the MROM card is shown for comparison at the right hand side. The dotted lines indicate the triangular shape of the bit pattern.

the array were read out in parallel, nine identical images with a translational shift over the sensor pitch distances were obtained, without any mutual interference.

To allow for a more detailed comparison between the measured and calculated signal, we collected line scans measured by a single MTJ. Several line scans for different $z$ values were taken in the $y$ direction: see Fig. 5. In this case a different medium was used, having bits at every site. To mimic the averaging effect of an MTJ sensor of $5 \times 1 \mu \mathrm{m}^{2}$ on the measured signal, the calculated magnetic field was taken as the average of 35 points, 7 in the $x$ direction and 5 in the $y$ direction. This proved to be a sufficient dense mesh for reliable averaging. As shown in Fig. 5, the measured signal oscillates over a range of $\sim 20 \mathrm{Oe}$, whereas the calculated signal oscillates over a range of $\sim 10$ Oe. Both have a period of $7 \mu \mathrm{m}$ and both have a tooth-like shape. The twin peaks in the measured signal are closer together than the calculated ones while the valleys are wider. This indicates that the magnetic poles of the bits are not at the edges of the bits but translated slightly inwards, which is to be expected when energetically favorable domains form at the short sides of the bit. Yet, the overall agreement between measured and calculated signal shows that the magnetic field description of the bits according to Eq. (1) is a useful approximation.

The line scans for different medium-sensor distances allow us to analyze the decay of the measured signal with the separation distance. To describe this decay for a periodic array of magnetic bits as a function of sensor-medium distance, it is convenient to use Fourier analysis. ${ }^{6}$ The decay of

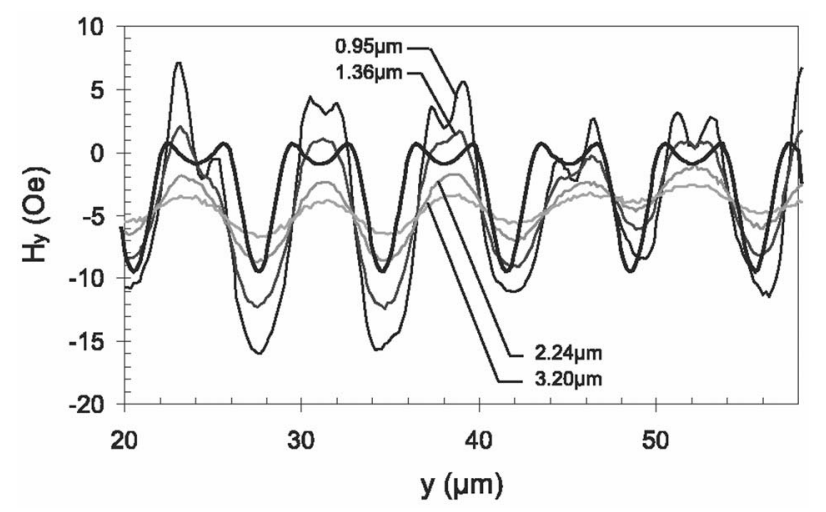

FIG. 5. Magnetic field Hy along a bit pattern on an MROM card, measured at the indicated sensor-medium separation distances $z$. For clarity, not all measured scans are shown. The bold line represents the magnetic field calculated with Eq. (1) for $z=0.95 \mu \mathrm{m}$. The lateral step size was $0.167 \mu \mathrm{m}$. 


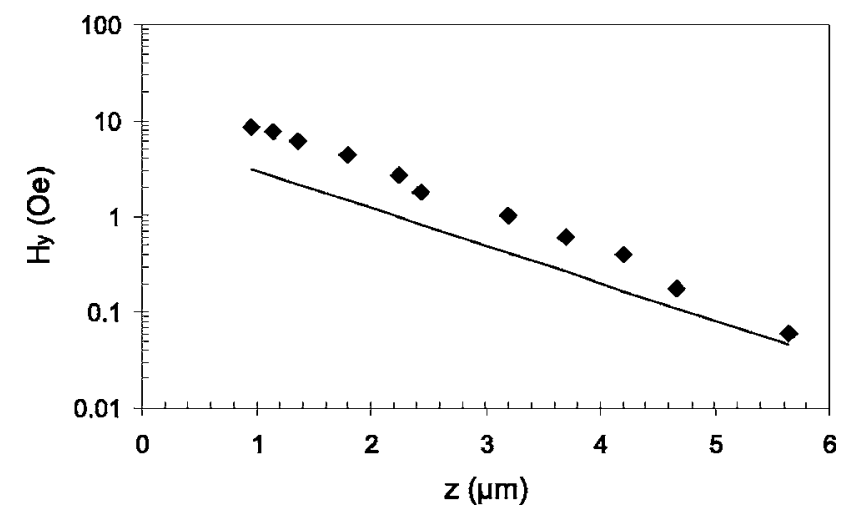

FIG. 6. Exponential decay of the measured magnetic field Hy with increasing medium-sensor distance $z$. The symbols represent the measurements, whereas the solid line represents the calculated values.

the magnetic field signal of a bit surrounded by other bits, as a function of the sensor-bit distance, may then be described by the following equation:

$$
H_{\mathrm{y}}[z]=H_{0} e^{-z \cdot \sqrt{k_{\mathrm{x}}^{2}+k_{\mathrm{y}}^{2}}},
$$

where $H_{0}$ is the coefficient of the Fourier component with the highest spatial wave numbers $k_{x}$ and $k_{y}$. Since the length of the MTJ element is larger than the pitch of the bit pattern in the $x$ direction, the highest wave number in the $x$ direction is in fact averaged out: $k_{x}=0$. Therefore, in our experiment the exponent in Eq. (3) transforms to $-0.90 \cdot z$ ( $z$ in $\mu \mathrm{m})$. The corresponding Fourier component can be calculated from Eq. (1) by a discrete Fourier transformation of the field of a single bit, ${ }^{7}$ from which $H_{0}=7.2$ Oe is obtained. Inserting this value in Eq. (3) yields the line plotted in Fig. 6; also plotted are the data points extracted from Fig. 5. For the larger separations there is a good match between the measured and calculated curve, while at smaller distances the differences are within a factor 2. Figure 6 clearly shows that the Fourier analysis correctly describes the decay of the bit signal as a function of the sensor-medium separation distance $z$, without any additional fit parameters.

This allows us to estimate how much the bit density may be increased considering the experienced shortest sensormedium distance of $0.93 \mu \mathrm{m}$ under ambient conditions as a strict limitation. With the same magnetic material but increasing the height of the mesas in the topography of the medium from 100 to $500 \mathrm{~nm}$, we can increase $H_{0}$ in Eq. (3) to $17 \mathrm{Oe}$. Assuming that signals of a tenth of the magnitude shown in Fig. 5 are still detectable and that a tenfold more sensitive MTJ is available, we recalculated $k$ for a square bit using Eq. (3). The value thus obtained corresponds to $5 \mathrm{Mbyte} / \mathrm{cm}^{2}$ as maximum achievable bit density.

In conclusion, a MROM concept is discussed featuring a removable data carrier with prerecorded magnetic bits. We show that medium cards with a density of around $0.5 \mathrm{Mbyte} / \mathrm{cm}^{2}$ can be read out. The critical scaling parameter is the medium-sensor separation distance, as the signal decays exponentially with this distance.

${ }^{1}$ B. N. Engel, J. Åkerman, B. Butcher, R. W. Dave, M. DeHerrera, M. Durlam, G. Grynkewich, J. Janesky, S. V. Pietambaram, N. D. Rizzo, J. M. Slaughter, K. Smith, J. J. Sun, and S. Tehrani, IEEE Trans. Magn. 41, 132 (2005).

${ }^{2}$ A. E. T. Kuiper, M. F. Gillies, V. Kottler, G. W. 't Hooft, J. G. M. van Berkum, C. van der Marel, Y. Tamminga, and J. H. M. Snijders, J. Appl. Phys. 89, 1965 (2001).

${ }^{3}$ K. L. Phan, H. Boeve, F. Vanhelmont, T. Ikkink, and W. Talen, IEEE Trans. Magn. 41, 3685 (2005).

${ }^{4}$ Th. G. S. M. Rijks, W. J. M. de Jonge, W. Folkerts, J. C. S. Kools, and R. Coehoorn, Appl. Phys. Lett. 65, 916 (1994).

${ }^{5}$ E. C. Stoner and E. P. Wohlfarth, Philos. Trans. R. Soc. London, Ser. A 240, 599 (1948).

${ }^{6} \mathrm{~S}$. X. Wang and A. M. Taratorin, Magnetic Information Storage Technology (Academic, London, 1999).

${ }^{7}$ W. L. Briggs and V. Emden Henson, The DFT: An Owner's Manual for the Discrete Fourier Transform (Society for Industrial and Applied Mathematics, Philadelphia, 1995). 